\title{
Study on the Contra-Rotating Propeller system design and full-scale performance prediction method
}

\author{
Keh-Sik Min, Bong-Jun Chang and Heung-Won Seo
}

Hyundai Heavy Industries, Co. Ltd., Ulsan, Korea

\begin{abstract}
A ship's screw-propeller produces thrust by rotation and, at the same time, generates rotational flow behind the propeller. This rotational flow has no contribution to the generation of thrust, but instead produces energy loss. By recovering part of the lost energy in the rotational flow, therefore, it is possible to improve the propulsion efficiency. The contra-rotating propeller (CRP) system is the representing example of such devices. Unfortunately, however, neither a design method nor a full-scale performance prediction procedure for the CRP system has been well established yet. The authors have long performed studies on the CRP system, and some of the results from the authors' studies shall be presented and discussed.
\end{abstract}

KEY WORDS: Contra-Rotating Propeller; Energy saving; Thrust; Rotational flow; Wake distribution; Propulsive efficiency

\section{INTRODUCTION}

Seaborne transportation is probably as old as the human race itself. Along such long history in this field, the fuel economy is becoming more and more important. In general, the fuel cost accounts for the largest portion of the overall cost of ship operation. Therefore, it could be easily recognized that reduction of fuel consumption is directly related to the improvement of the economy of ship operation.

Various methods and ideas have been proposed and utilized to achieve this goal. Superior hull form design, light structural design, optimum propeller design and selection of proper main engine(s) are some of major ways, together with the arrangements of special propulsion aid devices. Among the various propulsion-aid devices suggested and tried up to now, the contra-rotating propeller (CRP) system is considered to be the most significant one.

As well-known, a screw-propeller produces thrust by rotation and, at the same time, generates rotational flow behind the propeller as shown in Fig. 1. This rotational flow does not contribute to the generation of thrust, but instead causes a loss of energy. The CRP system could significantly improve the propulsion efficiency by recovering a part of the energy loss due to the rotational flow and, hence, could significantly reduce the fuel consumption.

Unfortunately, however, no optimum design process for a CRP system has been prepared yet. Furthermore, no generally accepted extrapolation procedure of model test data

Corresponding author: Keh-Sik Min

e-mail:minks@hhi.co.kr to full-scale information has been established up to nowadays. This fundamental problem is considered to come from our insufficient knowledge about the flow characteristics around the CRP system. As well recognized, the forward and the aft propellers of the CRP system interact each other and generate a much more complicated flow field around the system compared with that around a single-screw system. Accordingly, the wake and pressure distributions would be greatly altered from those for the individual propeller alone.

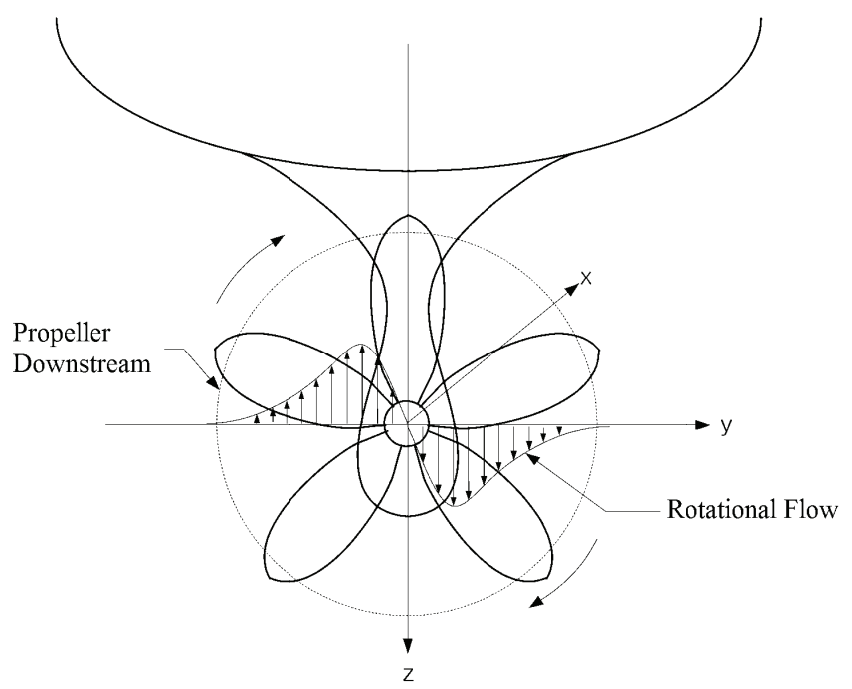

Fig. 1 Tangential velocity distribution inside the slip-stream for the propellers rotating in a clockwise direction. 
Measurement of the nominal wake in the position of the forward propeller plane without any propellers is nothing but a conventional process. Using a Laser Doppler Velocimetry (LDV), it is also possible to measure the axial and tangential wakes quite accurately in the position of the aft propeller plane with the forward propeller in operation. However, there is no way nowadays to be able to estimate the effective wake distribution around the CRP system with reasonable accuracy. Furthermore, it becomes much more complicated to estimate the alteration in the pressure distribution around propeller blades due to mutual interaction between the forward and the aft propellers. This is the present state of art in dealing with the CRP system.

The authors have made their long effort not only to investigate the flow characteristics around the CRP system, but also to establish a design method and an extrapolation technique (Min, 1995). The authors' effort does not seem to be much successful particularly in the view point of performance extrapolation. In this paper, some of the results from the authors' recent studies shall be presented and discussed.

\section{IMPORTANT DESIGN CHARACTERISTICS}

In the case of a CRP system, there are more characteristics to be considered compared with those in the case of a single screw system. The followings are some of important items:

- thrust distribution between the forward and the aft propellers

- rotational speed(RPM) of the forward and the aft propellers

- distance between two propellers (separation of two propellers)

- diameters of two propellers

- slipstreams of the forward and the aft propellers

Optimum information for the above items is not definite nowadays due to insufficient knowledge about the CRP system. Furthermore, it is not appropriate to discuss the above items independently, since most of them are interrelated each other. However, brief investigations shall be made for each of the above items based on the physical phenomena.

Table 1 Thrust distribution of fwd and aft propellers.

\begin{tabular}{|c|c|c|}
\hline \multirow{2}{*}{ Case } & \multicolumn{2}{|c|}{ Percent of thrust (\%) } \\
\cline { 2 - 3 } & Fwd Propeller & Aft Propeller \\
\hline 1 & 40.0 & 60.0 \\
\hline 2 & 50.0 & 50.0 \\
\hline 3 & 60.0 & 40.0 \\
\hline 4 & 70.0 & 30.0 \\
\hline
\end{tabular}

\section{Thrust Distribution}

In order to investigate the effect of thrust distribution between the forward and aft propellers on the overall propulsion efficiency, it was initially planned to design CRP systems according to various thrust combinations as shown in Table 1 . However, only two cases of the thrust combination, that is, thrust ratios of $60: 40$ and $50: 50$ for the forward and the aft propellers have been studied, since it takes considerable time and cost to manufacture a system.

\section{Rotational Speed}

In general, the aft propeller is directly connected to the main engine and hence, the RPM and the optimum diameter of the aft propeller are determined accordingly. The RPM of the forward propeller is reduced and the rotational direction is reversed by the contra-rotating gear system. Theoretically, the optimum reduction ratio could be selected. In practice, however, it is restricted due to various reasons such as type, size and strength of the gear system.

\section{Separation of Two Propellers}

The separation of two propellers, that is, the distance between the forward and the aft propellers should be considered from two physical aspects. One is the recovery of energy loss, and the other is the interaction between two propellers.

As mentioned, the physical reasoning for a CRP system to improve the propulsion efficiency is that the energy loss due to the rotational flow behind the forward propeller could partly be recovered by the aft propeller. From the view point of energy recovery, therefore, two propellers should be arranged as close as possible.

In the view point of pressure interaction, however, the situation is reversed. The aft propeller interacts in the way of decreasing the pressure of the pressure side of the forward propeller and, at the same time, the forward propeller interacts in the way of increasing the pressure of the suction side of the aft propeller. As a result, the overall thrust produced by the pressure difference is reduced. From the view point of the pressure interaction, therefore, two propellers should be located as far as possible.

Therefore, the two physical aspects, that is, the energy recovery and the pressure interaction are in the reverse relation. It is the authors' opinion that it is better to arrange two propellers as close as possible as long as there is no problem in shaft system, since the energy loss is directly related to the distance between two propellers, while the interaction effect is reversely related to the square of the distance of two propellers. In practice, it is considered to be better to reduce the distance between two propellers as much as possible to avoid disadvantages in shafting and other arrangements.

\section{Propeller Diameters and Slipstream}

In order to determine the diameter and the corresponding optimum RPM of the forward propeller, it is necessary to determine the distance between the two propellers in advance. 
Once the distance is decided, the optimum diameter of the forward propeller is decided from the relation of slipstreams of the two propellers.

A propeller slipstream has such characteristics that it is contracted rapidly in the region close to the propeller plane and reaches to an almost steady state at the distance of a propeller's radius from the propeller plane. It is the authors' opinion that it is better to determine the diameter of the forward propeller in such a way that slipstreams from the two propellers overlap each other as much as possible in the overall sense. Fig. 2 shows two typical cases of slipstream overlap. It is considered that the Case 2 is better than the Case 1 in Fig. 2.

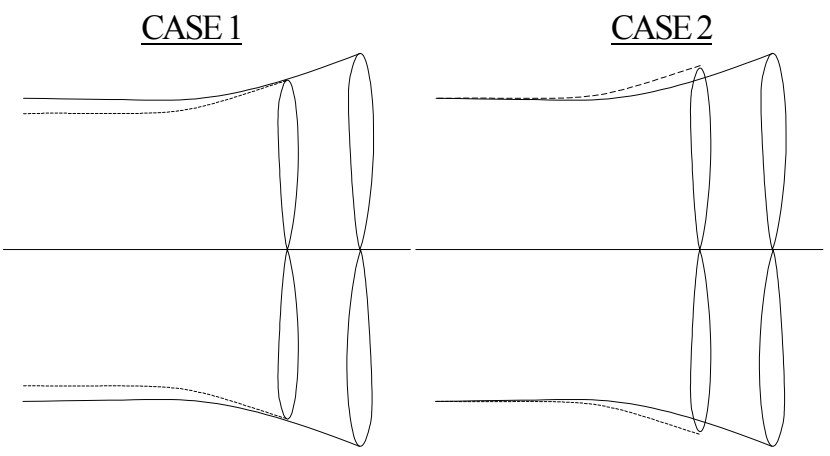

Fig. 2 Slipstreams of the forward and aft Propeller.

\section{Wake Distribution at the Propeller Planes}

Nowadays, the nominal wake distributions at the positions of the forward and the aft propeller planes could be measured quite accurately by LDV in model scale. In general, it is sufficient to know the axial wake information only to design the forward propeller. In order to design the aft propeller, however, it is necessary to know the tangential wake distribution as well as the axial distribution. Unfortunately, however, no method is available nowadays to estimate the effective axial and tangential wake distributions with sufficient accuracy for the practical design of a CRP system. For this study, therefore, the authors have specially prepared and utilized the design program of a CRP system using nominal wakes (Min, 1991).

\section{SELECTION OF THE OBJECT SHIPS}

In this study, two different types of ships, that is, a 300,000 ton deadweight VLCC and an 8,600 TEU Class Containership have been selected as the object ships. However, the type of ship may not make much difference in the study of the CRP system. As expected, similar amount of improvements in propulsion efficiency have been achieved by the CRP system for both of the object ships selected for this study. However, it is the authors' opinion that the application of CRP system is more suitable for fine higherspeed ships such as containerships than for full slow-speed ships such as oil tankers, because the power density to be absorbed by the CRP system and the absolute amount of fuel saving for containerships are much higher than those for oil tankers. In this paper, therefore, discussions shall be made only for the case of 8,600 TEU Class Containership due to limited space. Table 2 shows the principal characteristics of the selected ship.

Table 2 Main characteristics of 8,600 TEU Containership.

\begin{tabular}{|c|c|c|}
\hline \multicolumn{2}{|c|}{ Length between Perpendiculars (LPP) } & $319.0 \mathrm{~m}$ \\
\hline \multicolumn{2}{|l|}{ Beam (B) } & $42.8 \mathrm{~m}$ \\
\hline \multicolumn{2}{|l|}{$\operatorname{Draft}(\mathrm{T})$} & $13.0 \mathrm{~m}$ \\
\hline \multicolumn{2}{|c|}{ Displacement $(\Delta)$, } & 119,289 ton \\
\hline \multicolumn{2}{|c|}{ Block Coefficient $\left(\mathrm{C}_{\mathrm{B}}\right)$} & 0.6557 \\
\hline \multicolumn{2}{|c|}{ Design Speed $\left(\mathrm{V}_{\mathrm{S}}\right)$} & 25.0 knots \\
\hline \multirow{2}{*}{ Propeller } & Diameter (D) & $9.1 \mathrm{~m}$ \\
\hline & Number of Blades (k) & 6 \\
\hline
\end{tabular}

\section{DESIGN OF THE SYSTEM}

Design conditions have been selected according to the directions and the physical aspects discussed in the previous section. In order to design the forward propeller, the axial flow velocity distribution has been measured at the forward propeller plane. The selected design condition and the circumferentially averaged axial nominal wake distribution are shown in Table 3 and Fig. 3, respectively.

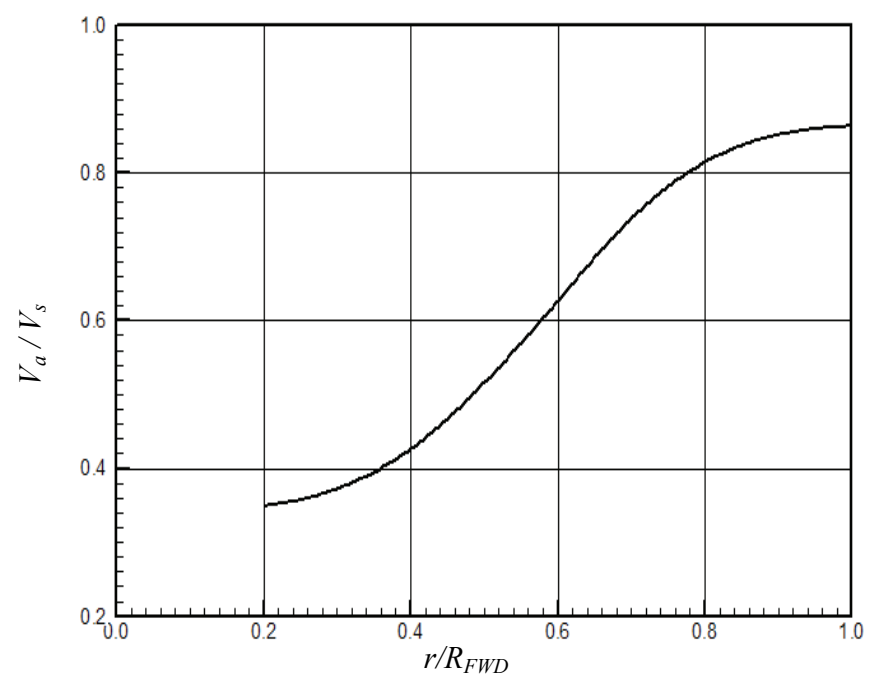

Fig. 3 Circumferentially averaged nominal axial velocity distribution.

Planform and section data have been prepared according to the design conditions summarized in Table 3, and the forward propeller has been designed through the optimization process. In order to design the aft propeller, axial and 
tangential flow distributions at the aft propeller plane were measured while operating the forward propeller according to the design condition. Figs. 4 5 show the circumferentially averaged axial and tangential velocity distributions, respectively.

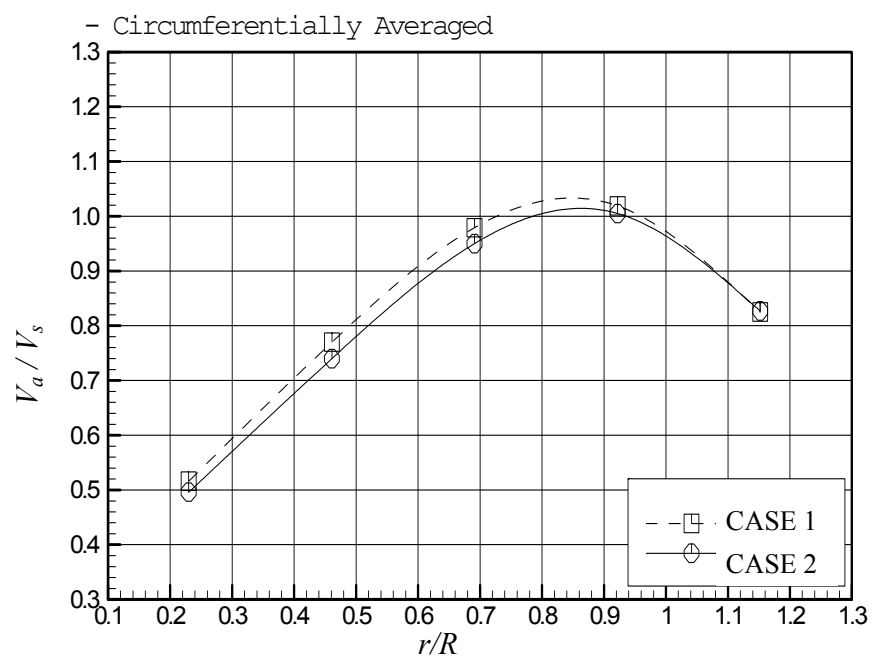

Fig. 4 Axial velocity distribution at the aft-propeller plane.
After preparing planform and section data, the aft propeller was designed through the optimization process for the flow distributions as shown in Figs. 4 5.

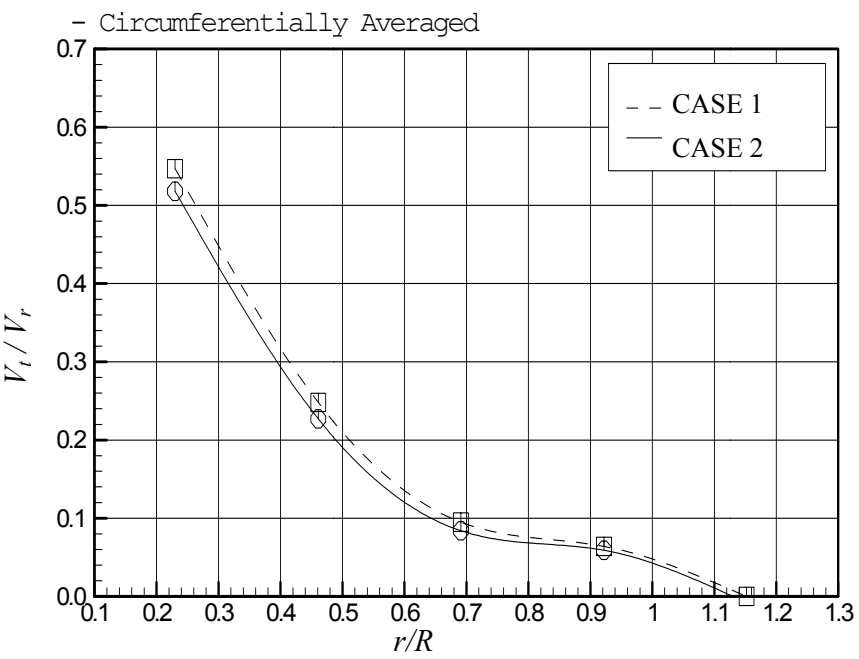

Fig. 5 Tangential velocity distribution at the aft-propeller plane.

Table 3 Design condition for the CRP system.

\begin{tabular}{|c|c|c|c|c|}
\hline \multirow[b]{2}{*}{ Characteristics } & \multicolumn{2}{|c|}{ CASE 1} & \multicolumn{2}{|c|}{ CASE 2} \\
\hline & $\begin{array}{l}\text { Forward } \\
\text { Propeller }\end{array}$ & $\begin{array}{c}\text { Aft } \\
\text { Propeller }\end{array}$ & $\begin{array}{l}\text { Forward } \\
\text { Propeller }\end{array}$ & $\begin{array}{c}\text { Aft } \\
\text { Propeller }\end{array}$ \\
\hline Power Ratio & $60 \%$ & $40 \%$ & $50 \%$ & $50 \%$ \\
\hline Diameter $(m)$ & 9.1 & 7.9 & 9.1 & 7.9 \\
\hline Number of Blades & 5 & 4 & 5 & 4 \\
\hline RPM & 70.1 & 93.5 & 70.1 & 93.5 \\
\hline Distance Between Propellers $(m)$ & \multicolumn{4}{|c|}{2.067} \\
\hline NCR & \multicolumn{4}{|c|}{ 76,320 PS $\times 93.5 R P M^{*}$} \\
\hline Ship Speed $(V s)$ & \multicolumn{4}{|c|}{25.7 knots } \\
\hline
\end{tabular}

* Including $3 \%$ RPM Margin.

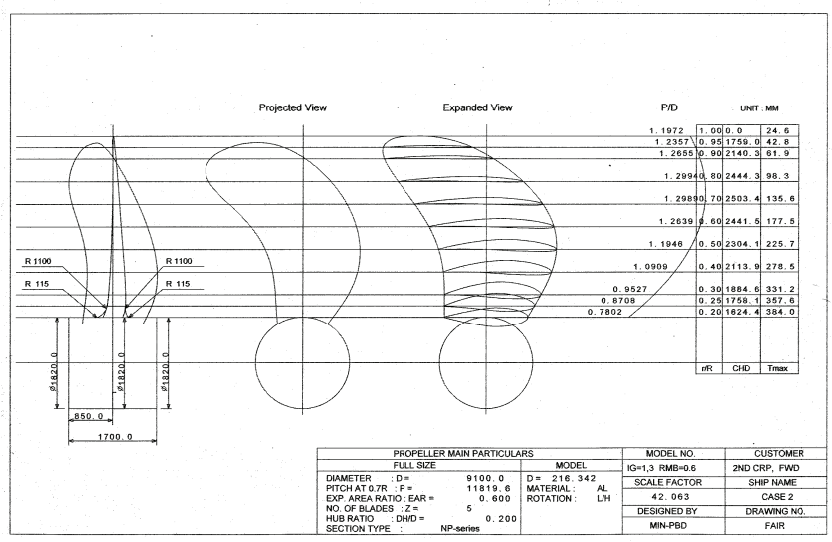

Fig. 6 Characteristics of the 2nd-designed forward propeller for Case 2.

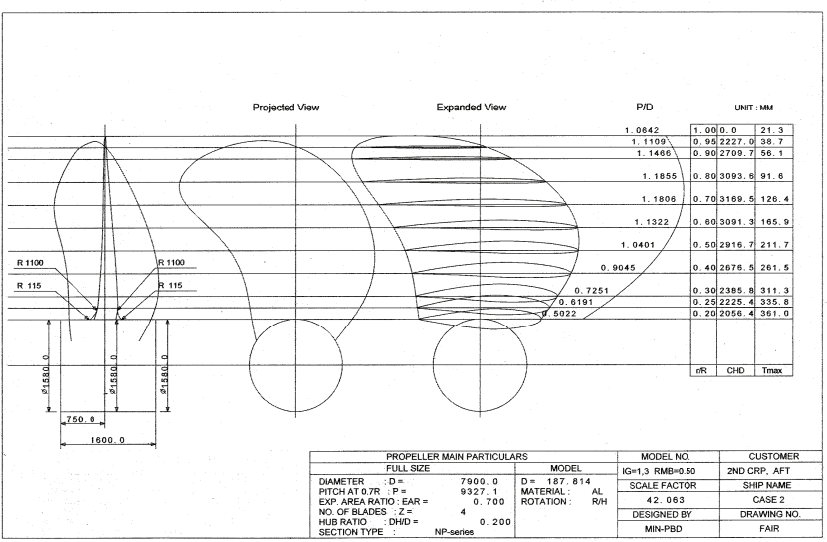

Fig. 7 Characteristics of the 2nd-designed aft-Propeller for Case 2. 
Upon completion of the CRP system design, model systems were manufactured and model tests were carried out. From the test results, it was confirmed that a significant improvement in propulsion efficiency has been achieved. However, the ratio of the power absorbed by the forward and the aft propellers was not within the reasonable range of agreement with the design condition. Therefore, it was decided to modify the original (the first) design of the CRP system so that the design condition would be reasonably satisfied. Figs. 6 and 7 show the characteristics of the redesigned (the 2nd design) forward and the aft propellers for the Case 2, respectively.

\section{MODEL TEST AND TEST RESULTS}

Model tests for the performance evaluation were carried out whenever the CRP system design was completed. Models of CRP systems were manufactured in aluminum in the scale of the existing model ship with single screw. This scale ratio is $1 / 42.063$. Fig. 8 shows the aluminum model of the redesigned (the 2nd design) CRP system for the Case 2.

For all the CRP systems, the following tests were conducted at the deep-water towing tank of Maritime Research Institute, Hyundai Heavy Industries (HMRI).

- propeller open-water tests for each of the forward and aft propellers.

- open-water tests for CRP system

- self-propulsion tests by each forward and aft propeller alone

- self-propulsion tests by CRP system

- axial and tangential flow measurements behind CRP system

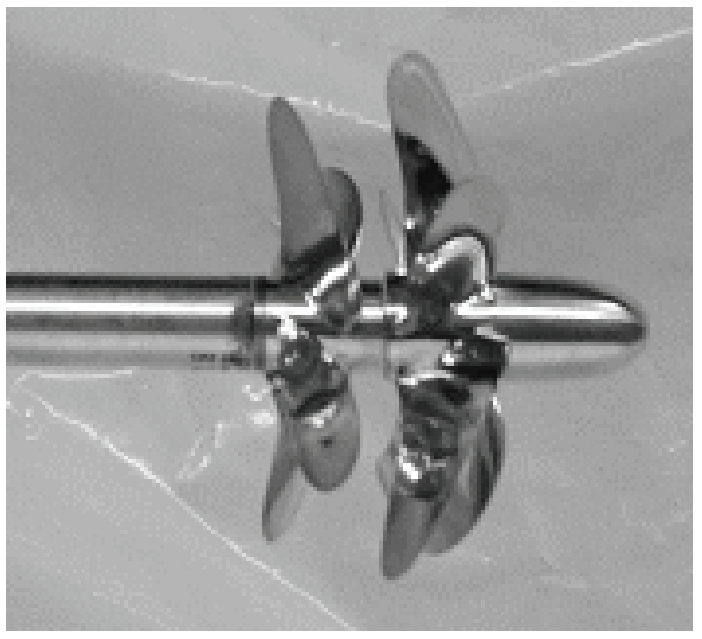

Fig. 8 The $2^{\text {nd }}$ designed CRP system model for the Case 2 .

Figs. 9 10 show the propeller open-water test results of each of the re-designed (the 2nd design) forward and aft propeller for the Cases 1 and 2, respectively. Fig. 11 shows the open-water test result of the re-designed CRP systems. The open-water test results of CRP systems have been nondimensionalized based on the quantities of the forward propeller.

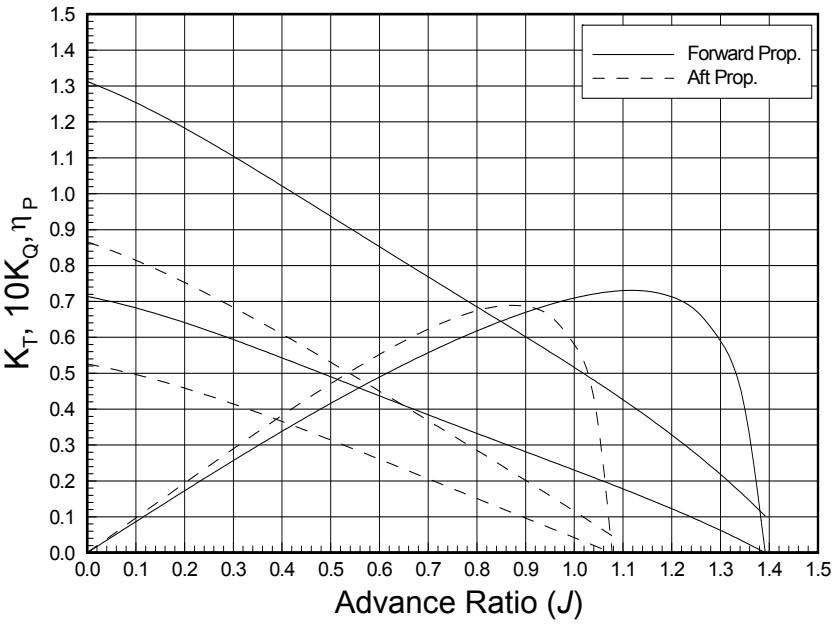

Fig. 9 Open water characteristics of the 2nd-designed independent propellers for Case 1.

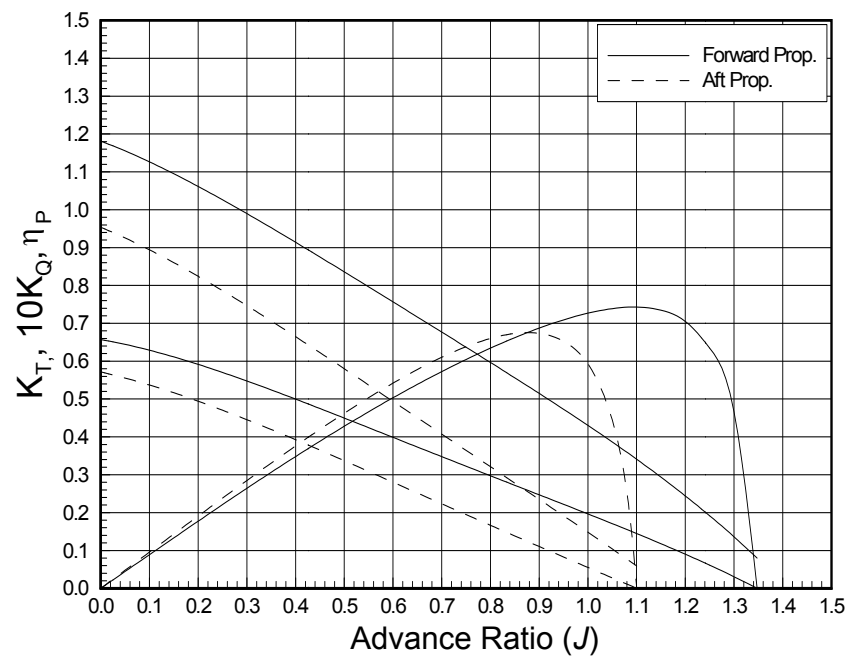

Fig.10 Open water characteristics of the 2nd-designed independent propellers for Case 2.

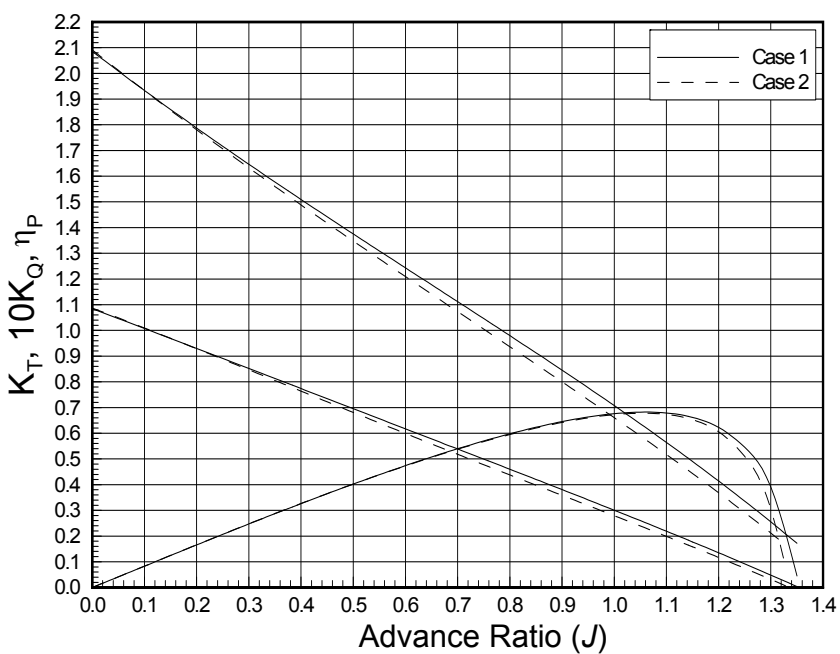

Fig. 11 Open water characteristics of the 2nd-designed CRP system. 


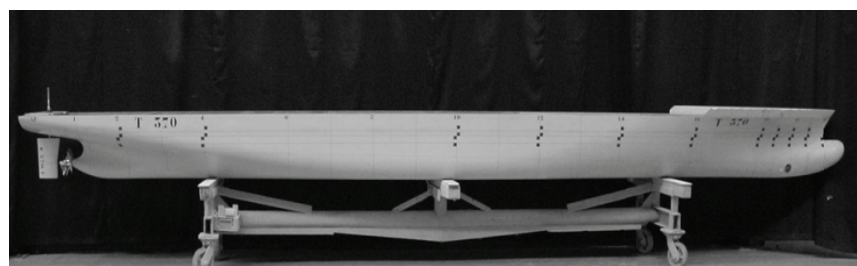

Fig. 12 The model ship with the CRP system.

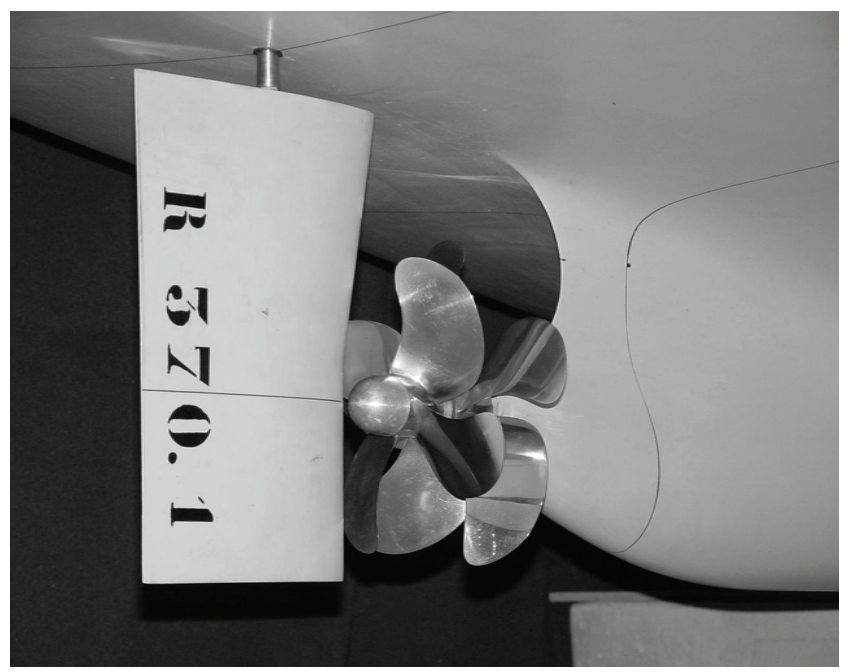

Fig. 13 The CRP system at the stern of the model ship.

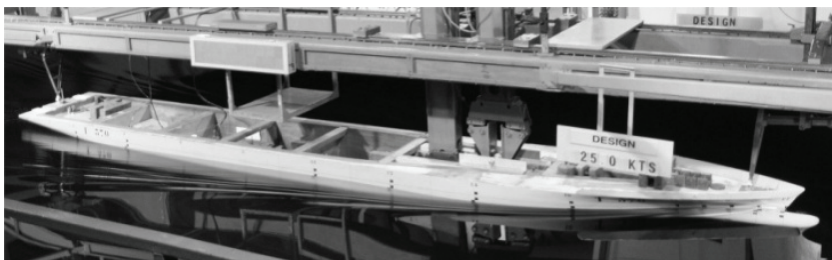

Fig. 14 The self-propulsion test with CRP system.

Figs. 12 13 show model ships with the CRP system, and Fig. 14 shows the self-propulsion test at the deep-water towing tank. As mentioned earlier, self-propulsion tests with individual propeller were also carried out as references, but shall not be discussed in this paper. Self-propulsion tests were conducted in the following way:

- differential force due to the difference in frictional resistance coefficient between model ship and full-scale ship was applied as usual.

- rotational speed ratio between the forward and aft propellers was always kept constant with that of the design condition.

- thrust and torque of the forward and aft propellers were measured independently.

Some of the test results are summarized in Tables $4 \& 5$.

As shown in Table 5, the thrust ratios of the two propellers in the model tests are considerably different from those of the design condition for the 1st design of the CRP system. However, they are in reasonable agreement for the 2 nd design.

Table 4 Self-propulsion test results of the CRP system.

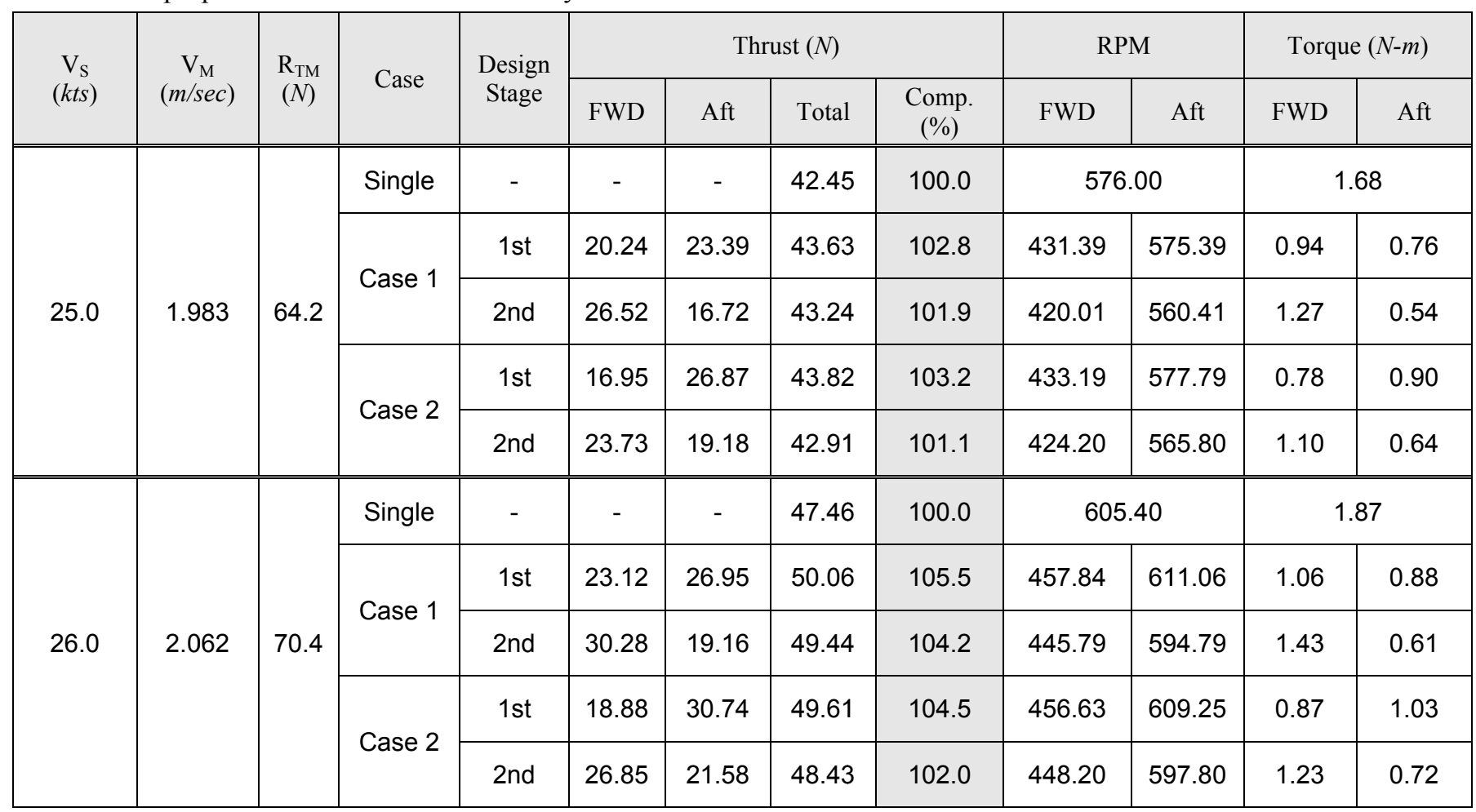


Table 5 Thrust ratio between the forward and aft propellers.

\begin{tabular}{|c|c|c|c|c|c|c|c|c|}
\hline \multirow{3}{*}{$\begin{array}{c}\mathrm{V}_{\mathrm{S}} \\
(k t s)\end{array}$} & \multirow{3}{*}{ Case } & \multirow{3}{*}{$\begin{array}{c}\text { Design } \\
\text { Stage }\end{array}$} & \multicolumn{6}{|c|}{ Thrust $(N)$} \\
\hline & & & \multicolumn{3}{|c|}{ FWD Propeller } & \multicolumn{3}{|c|}{ Aft Propeller } \\
\hline & & & Target & Meas. & $\operatorname{Diff}(\% *)$ & Target & Meas. & $\operatorname{Diff}(\% *)$ \\
\hline \multirow{4}{*}{25.0} & \multirow{2}{*}{ Case 1} & $1^{\text {st }}$ & \multirow{2}{*}{25.18} & 20.24 & -19.62 & \multirow{2}{*}{16.78} & 23.39 & 39.36 \\
\hline & & $2^{\text {nd }}$ & & 26.52 & 5.33 & & 16.72 & -0.37 \\
\hline & \multirow{2}{*}{ Case 2} & $1^{\text {st }}$ & \multirow{2}{*}{20.98} & 16.95 & -19.21 & \multirow{2}{*}{20.98} & 26.87 & 28.09 \\
\hline & & $2^{\text {nd }}$ & & 23.73 & 13.11 & & 19.18 & -8.58 \\
\hline \multirow{4}{*}{26.0} & \multirow{2}{*}{ Case 1} & $1^{\text {st }}$ & \multirow{2}{*}{28.25} & 23.12 & -18.18 & \multirow{2}{*}{18.84} & 26.95 & 43.04 \\
\hline & & $2^{\text {nd }}$ & & 30.28 & 7.19 & & 19.16 & 1.69 \\
\hline & \multirow{2}{*}{ Case 2} & $1^{\mathrm{st}}$ & \multirow{2}{*}{23.55} & 18.88 & -19.85 & \multirow{2}{*}{23.55} & 30.74 & 30.52 \\
\hline & & $2^{\text {nd }}$ & & 26.85 & 14.01 & & 21.58 & -8.37 \\
\hline
\end{tabular}

* Based on Target

\section{EXTRAPOLATION METHODS}

As is well known, a generally accepted method from model test results to full-scale ship performance prediction for a CRP system has not been prepared yet. In this study, therefore, four different methods have been prepared and tested including MARIN's method.

First of all, characteristics of individual model propellers have been converted to those for full scale propellers using the method adopted at the 15th ITTC(1978). In this method, thrust and torque coefficients are adjusted utilizing the following relations

$$
\begin{aligned}
& C_{D M}=2\left(1+2 \frac{t}{c}\right)\left[\frac{0.044}{R n^{1 / 6}}-\frac{5}{R n^{2 / 3}}\right] \\
& C_{D S}=2\left(1+2 \frac{t}{c}\right)\left[1.89+1.62 \log \frac{c}{k}\right]^{-2.5} \\
& \Delta C_{D}=C_{D M}-C_{D S} \\
& \Delta K_{T}=-\Delta C_{D} \cdot 0.3 \cdot \frac{P}{D} \cdot \frac{c N}{D} \\
& \Delta K_{Q}=\Delta C_{D} \cdot 0.25 \cdot \frac{c N}{D} \\
& K_{T S}=K_{T M}-\Delta K_{T} \\
& K_{Q S}=K_{Q M}-\Delta K_{Q}
\end{aligned}
$$

Here, various symbols represent the following:

$t$ and $c$ : blade thickness and chord at $70 \%$ of radius from the propeller center

$C_{D M}, C_{D S}$ : drag coefficient for the model and full scale propellers, respectively

$k_{p}$ : surface roughness for full-scale propellers ( $30 \mu \mathrm{m}$ in general)

Each of four full-scale ship performance prediction methods, that is, extrapolation methods tested in this study shall be briefly introduced and discussed

\section{Method 1 (MARIN)}

- individual thrust and torque of the forward and aft propellers measured from the model test are nondimensionalized by the characteristics of the forward propeller as follows(Van Manen, 1968):

$$
\begin{aligned}
& J=V_{a} / n_{f} D_{f} \\
& K_{T}=\left(T_{f}+T_{a}\right) / \rho n_{f}^{2} D_{f}^{4} \\
& K_{Q}=\left(n_{f} Q_{f}+n_{a} Q_{a}\right) / \rho n_{f}^{3} D_{f}^{5}
\end{aligned}
$$

- characteristics of the model system are corrected to those of the full-scale system by the ITTC 78 method, that is, by the relation (1).

- full-scale ship performance is estimated by the same procedure that utilized in the case of a single screw propeller system. 


\section{Method 2 (HMRI Method 1)}

- the effective wake fraction and the relative rotative efficiency in model scale are determined from the propeller open-water and the self-propulsion tests based on the thrust identity principles.

- full-scale ship effective wake fraction is estimated from that for the model ship using the ITTC equation for model shipfull scale ship relation.

- the self-propulsion point and RPM for the forward propeller are determined from the measured $K_{T} / J^{2}-J$ relation.

- RPM of the aft propeller is determined by the RPM ratio, that is, the gear ratio.

- the self-propulsion point and the effective wake fraction for the aft propeller are determined from the measured $K_{T} / J^{2}-J$ relation.

\section{Method 3 (HMRI Method 2)}

- basically, method 3 is the same procedure as stated in method 2, except using $K_{T} / J$ - $J$ relation instead of $K_{T} / J^{2}-J$ relation to find the full-scale ship self-propulsion points for the forward and aft propellers, respectively.

\section{Method 4 (HMRI Method 3)}

- characteristics of each of the forward and aft propellers of the model CRP system are estimated by the CRP system design program (Min, 1991).

- characteristics of each of the forward and aft propellers of the full-scale CRP system are also estimated using the same method.

- the theoretical relation between the model system and the full-scale system is derived.

- the full-scale system performance characteristics are obtained by applying the derived relation.

Table 6 Full-scale performance prediction according to the prediction method - Case 2, 2nd-designed CRP system. $\left(V_{s}=25.5 \mathrm{knots}, \quad R_{T}=2,935 \mathrm{kN}, \mathrm{EHP}=38,500 \mathrm{~kW}\right)$

\begin{tabular}{|c|c|c|c|c|c|c|c|c|c|c|c|}
\hline \multirow{2}{*}{ Method } & \multicolumn{2}{|c|}{ RPM } & \multicolumn{2}{|c|}{$T(k N)$} & \multicolumn{2}{|c|}{$Q(k N-m)$} & \multicolumn{3}{|c|}{ DHP $(k W)$} & \multirow{2}{*}{$\eta_{D}{ }^{*}$} & \multirow{2}{*}{$\begin{array}{r}\text { Comp } \\
(\%)\end{array}$} \\
\hline & FWD & Aft & FWD & Aft & FWD & Aft & FWD & Aft & Total & & \\
\hline Single & \multicolumn{2}{|c|}{92.41} & \multicolumn{2}{|c|}{3,642} & \multicolumn{2}{|c|}{5,748} & \multicolumn{3}{|c|}{55,619} & 0.691 & 100.0 \\
\hline 1 & \multicolumn{2}{|c|}{70.34} & \multicolumn{2}{|c|}{3,687} & \multicolumn{2}{|c|}{7,009} & \multicolumn{3}{|c|}{51,629} & 0.744 & 107.7 \\
\hline 2 & 68.34 & 91.15 & 2,042 & 1,646 & 3,853 & 2,219 & 27,574 & 21,184 & 48,758 & 0.788 & 114.1 \\
\hline 3 & 67.52 & 90.07 & 1,942 & 1,566 & 3,684 & 2,118 & 26,051 & 19,980 & 46,031 & 0.835 & 120.8 \\
\hline 4 & 67.26 & 89.71 & 1,929 & 1,555 & 3,512 & 1,921 & 24,732 & 18,044 & 42,776 & 0.898 & 130.0 \\
\hline
\end{tabular}

$* \eta_{D}=$ EHP / DHP : propulsive efficiency

Table 7 Comparison of propulsion efficiency between single and CRP systems.

\begin{tabular}{|c|c|c|c|c|c|c|c|c|}
\hline $\mathrm{V}_{\mathrm{M}}(\mathrm{m} / \mathrm{sec})$ & $F n$ & Case & $\begin{array}{r}\text { Design } \\
\text { Stage } \\
\end{array}$ & $R_{T M}(N)$ & $\operatorname{EHP}(W)$ & DHP $(W)$ & P. C.* & Comp. (\%) \\
\hline \multirow{5}{*}{1.983} & \multirow{5}{*}{0.231} & Single & - & \multirow{5}{*}{64.2} & \multirow{5}{*}{127.3} & 201.8 & 0.631 & 100.0 \\
\hline & & \multirow{2}{*}{ Case 1} & $1 \mathrm{st}$ & & & 187.1 & 0.680 & 107.9 \\
\hline & & & 2nd & & & 179.9 & 0.707 & 112.1 \\
\hline & & \multirow{2}{*}{ Case 2} & $1 \mathrm{st}$ & & & 189.1 & 0.673 & 106.7 \\
\hline & & & 2nd & & & 187.1 & 0.680 & 107.9 \\
\hline \multirow{5}{*}{2.062} & \multirow{5}{*}{0.240} & Single & - & \multirow{5}{*}{70.4} & \multirow{5}{*}{145.2} & 246.3 & 0.590 & 100.0 \\
\hline & & & $1 \mathrm{st}$ & & & 211.8 & 0.686 & 116.3 \\
\hline & & Case & 2nd & & & 210.8 & 0.689 & 116.8 \\
\hline & & \multirow{2}{*}{ Case 2} & $1 \mathrm{st}$ & & & 215.8 & 0.673 & 114.2 \\
\hline & & & 2nd & & & 213.7 & 0.680 & 115.3 \\
\hline
\end{tabular}

\footnotetext{
* Transmission efficiency not included
} 
Full-scale ship performance characteristics for the 2nd design of the Case 1 have been analyzed by each of four different methods and are summarized in Table 6. As shown in Table 6, there are big differences in the results of prediction according to methods. As reference, propulsion efficiencies for four different CRP system designs in model scale have been estimated by calculating effective and delivered powers and are summarized in Table 7 together with the propulsion efficiency for the single screw system. It is customary nowadays to apply the coefficient between model ship and full-scale ship when conducting model selfpropulsion tests. However, the delivered horsepower (DHP) shown in Table 7 has been derived from the torque and the RPM measured through the pure self-propulsion tests without applying the differential force. In other words, the tests are not model tests, but actual propulsion tests for small ships. It is the authors' opinion, therefore, that Table 7 may suggest the lower limit in the improvement of propulsion efficiency by the CRP system differential force due to the difference in the frictional resistance.

\section{DISCUSSIONS}

The CRP system is a device improving propulsion efficiency by recovering part of the energy in the rotating flow generated behind a screw propeller due to rotation of the propeller. Improvement of propulsion efficiency means the saving of fuel as much as the amount of improvement.

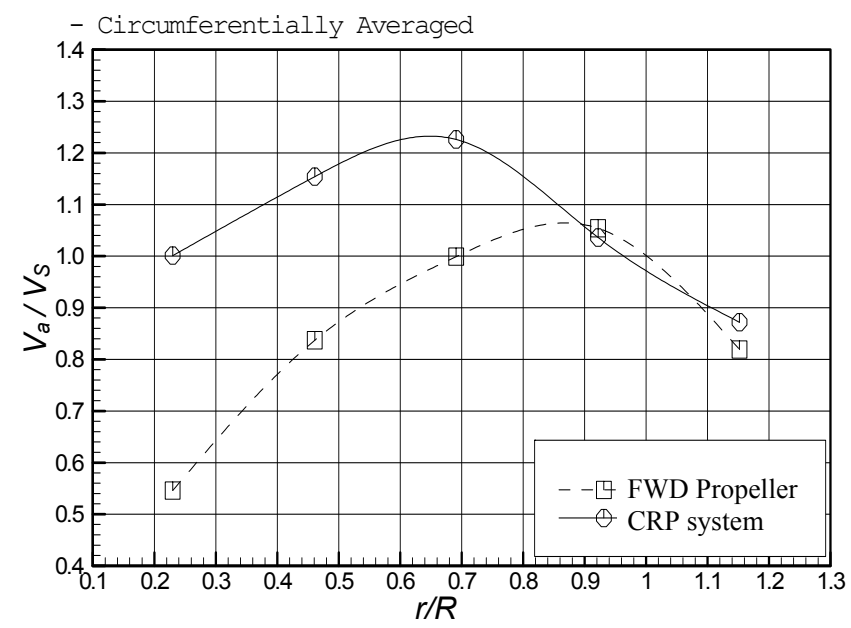

Fig. 15 Circumferentially averaged axial velocity distribution for the 2nd design of the Case 2.

In order to investigate the physical support of the energy recovery, flows have been measured at about one radius distance behind the CRP system with only the forward propeller in operation(without the aft propeller) and with normal operation of the system. Figs. 15 and 16 show circumferentially averaged axial and tangential flow velocities for the 2nd design system of the Case 2, respectively. As shown in Figs. 15 16, the axial flow has been accelerated by the system, while the rotating flow generated by the rotation of the forward propeller has been almost cancelled by the counter-rotation of the aft propeller, which means that most of the energy loss at the forward propeller is recovered by the aft propeller

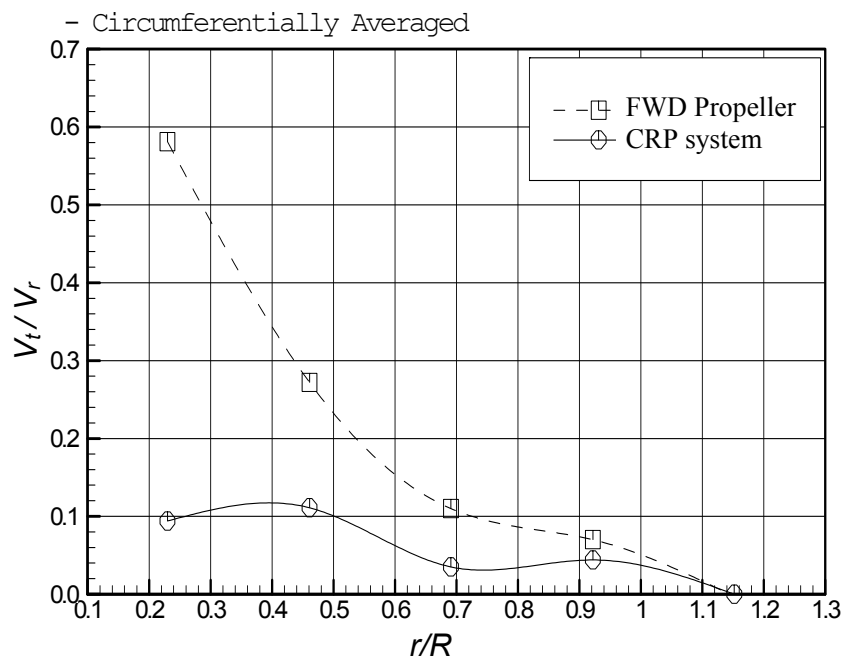

Fig. 16 Circumferentially averaged tangential velocity distribution for the 2nd design of the Case 2.

The authors have discussed four extrapolation methods in the previous section. As summarized in Table 6, the range of improvement in propulsion efficiency varies from 7.7 to $30.0 \%$ depending on the method. The actual amount of improvement for full-scale ships is not known definitely, since any reliable extrapolation method or procedure from model scale information to full-scale performance has not been established yet. From the physical aspects, however, improvement in full-scale ships would be greater than that in model scale, because the effect of viscosity is considerably less for full-scale ships.

\section{CONCLUSIONS}

In this paper, some results of the authors' recent study on the design and the performance prediction methods of the CRP system have been briefly presented and discussed together with specific example for the object ship of an 8,600 TEU class containership. From the discussions made up to now, the following conclusions could be derived:

- Propulsion efficiency is significantly improved by a CRP system, and hence, the same amount of fuel-saving could be achieved together with specific example for the object ship of an 8,600 TEU Class Containership. From the discussions made up to now, the following conclusions could be derived: 
- Propulsion efficiency is significantly improved by a CRP system, and hence, the same amount of fuel-saving could be achieved.

- Extrapolation methods 1 and 2 are not considered to be correct. Method 3 is rather conservative, while method 4 seems to be optimistic, but reasonable. It is disappointing that no definite conclusion on the reliability could be derived from this study.

- The amount of improvement in model scale can be regarded as the lower limit of that in full-scale ships. For the time being, therefore, it is recommended to select $2-3 \%$ higher amount of improvement in propulsion efficiency for fullscale ships than that of model scale ships, reflecting the fact that the performance of full-scale propeller is generally improved by $2 \sim 3 \%$ from that of model scale for the case of single screw.

It is the authors' belief that almost all lost energy due to the rotational flow except the frictional loss can be recovered by the CRP system, if the system is properly designed.

\section{REFERENCES}

Min, K.-S., 1991. Propeller Blade Section Design by Conformal Transformation Theory. The Proceedings of the International Workshop on the Propulsor Technology '91, Daejeon, Korea.

Min, K.-S. Lee, H.-G. and Kwak, Y.-K., 1995. Design and Performance Prediction of a Contra-Rotating Propeller for 300,000 TDW Class Tanker. The Proceeding of PRADS '95, Seoul, Korea

Van Manen J. D. and Oosterveld M. W. C., 1968. Model Tests on Contrarotating propellers. 7th Symposium on Naval Hydrodynamics, Rome, Italy. 